\title{
A educação popular na internet em tempos de pandemia
}

Evandro Ricardo Guindani ${ }^{1}$, Joel Felipe Guindani ${ }^{2}$, Yáscara Michele Neves Koga ${ }^{3}$, Tatiana Fraga Pastre $^{4}$, Deivis Eduardo Alves Leite ${ }^{5}$

\section{Resumo}

Este texto apresenta uma experiência de produção de conteúdo educativo durante o período da pandemia COVID-19 que assola o nosso país desde 2020. A necessidade de um maior diálogo com os alunos e com a comunidade provocou a iniciativa da criação de novas estratégias comunicacionais. Partindo da concepção de educação popular, um grupo de professores(as) universitários e acadêmicos(as) criou o projeto Educação popular nas redes com o objetivo de produzir textos e vídeos reflexivos fundamentados em conceitos teóricos, porém de fácil compreensão para todas as pessoas. O projeto se concretizou por meio da produção e publicação de vídeos e textos para o YouTube, redes sociais (Facebook) e aplicativos de conversa (WhatsApp). Os resultados demonstraram que houve uma aceitação do público, e o material produzido consegue dialogar - por meio de conceitos científicos - com a comunidade que está fora do ambiente acadêmico.

\section{Palavras-chave}

Educação popular. Internet. Universidade. Comunidade.

\footnotetext{
${ }^{1}$ Doutor em Educação pela Universidade Federal de Santa Catarina, Brasil; professor adjunto da Universidade Federal do Pampa, São Borja, Rio Grande do Sul, Brasil; coordenador do Canal Ciêncialiberta. E-mail: evandroricardo1@gmail.com.

2 Doutor em Comunicação e Informação pela Universidade Federal do Rio Grande do Sul, Brasil; professor adjunto da Universidade Federal de Santa Maria, Rio Grande do Sul, Brasil; membro do Grupo de Pesquisa Processos e Práticas em Atividades Criativas e Culturais (UNIPAMPA/CNPq). E-mail: j.educom@gmail.com.

3 Doutora em Educação pela Pontifícia Católica de São Paulo, Brasil; professora adjunta da Universidade Federal do Pampa, São Borja, Rio Grande do Sul, Brasil. E-mail: yascarakoga@gmail.com.

${ }^{4}$ Graduanda em Ciências Humanas na Universidade Federal do Pampa, Rio Grande do Sul, Brasil. E-mail: tatianapastre.aluno@unipampa.edu.br.

${ }^{5}$ Graduando em Ciências Humanas na Universidade Federal do Pampa, Rio Grande do Sul, Brasil E-mail: deivisleite.aluno@unipampa.edu.br.
} 


\title{
Popular education on the internet in times of pandemic
}

Evandro Ricardo Guindani ${ }^{6}$, Joel Felipe Guindani ${ }^{7}$, Yáscara Michele Neves Koga ${ }^{8}$, Tatiana Fraga Pastre $^{9}$, Deivis Eduardo Alves Leite ${ }^{10}$

\begin{abstract}
This text presents an experience in the production of educational content during the period of the COVID-19 pandemic that has been devastating our country since 2020 . The need for greater dialogue with students and the community led to the initiative of creating new communication strategies. Based on the concept of popular education, a group of professors created the project Popular education in Networks with the aim of producing reflective texts and videos based on theoretical concepts, but accessible for all people. The project was implemented through the production and publication of videos and texts for YouTube, social networks (Facebook) and messenger apps (WhatsApp). The results demonstrated that there was public acceptance and the material produced manages to dialogue - through scientific concepts - with the community outside the academic environment.
\end{abstract}

\section{Keywords}

Popular education. Internet. University. Community.

\footnotetext{
${ }^{6} \mathrm{PhD}$ in Education, Federal University of Santa Catarina, Brazil; adjunct professor at the Federal University of Pampa, São Borja, Rio Grande do Sul, Brazil; coordinator of the Ciêncialiberta Channel. E-mail: evandroricardo1@gmail.com.

${ }^{7} \mathrm{PhD}$ in Communication and Information, Federal University of Rio Grande do Sul, Brazil; adjunct professor at the Federal University of Santa Maria, Rio Grande do Sul, Brazil; member of the Research Group Processes and Practices in Creative and Cultural Activities (UNIPAMPA/CNPq). E-mail: j.educom@gmail.com.

${ }^{8} \mathrm{PhD}$ in Education, Pontifical Catholic of São Paulo, Brazil; adjunct professor at the Federal University of Pampa, São Borja, Rio Grande do Sul, Brazil. E-mail: yascarakoga@gmail.com.

${ }^{9}$ Undergraduate student in Human Sciences, Federal University of Pampa, Rio Grande do Sul, Brazil. E-mail: tatianapastre.aluno@unipampa.edu.br.

${ }^{10}$ Undergraduate student in Human Sciences, Federal University of Pampa, Rio Grande do Sul, Brazil. E-mail: deivisleite.aluno@unipampa.edu.br.
} 


\section{Introdução}

A Universidade, assim como qualquer instituição, sempre corre o risco de se "enclausurar", ou seja, de perder um contato mais direto e permanente com a comunidade. Para que isso não ocorra é fundamental que nós professores(as) e acadêmicos(as) sempre busquemos desenvolver ações comunicacionais que promovam um diálogo com a comunidade externa por meio da produção e socialização da ciência na perspectiva da construção coletiva do conhecimento.

Uma realidade que se fez presente no país neste período de pandemia COVID-19 foi o surgimento de ideias e crenças que questionavam a ciência e o conhecimento produzido dentro das universidades. Desde o início de 2019, com a chegada ao poder de políticos mais alinhados ao conservadorismo, grupos que se sentiram de certa forma legitimados politicamente, começaram a fazer uma série de ataques aos cursos da área das humanidades, como Filosofia, História, Sociologia e outros. Essa área do conhecimento foi acusada de fazer apologia ao "comunismo", numa clara demonstração de que esses grupos desconheciam totalmente o conceito de "comunismo" ou "marxismo".

Esses ataques às universidades, e mais especificamente, às humanidades, continuaram no ano de 2020 com o agravante do início da pandemia COVID-19, que desde então, no Brasil, está matando milhares de pessoas. Dentre os inúmeros prejuízos que toda a população teve, um deles foi o confinamento domiciliar. Sabemos que o trabalho remoto é privilégio de uma parcela reduzida da população, e que a maioria dos trabalhadores precisou sair de suas casas, se expondo à possibilidade de contrair o vírus. Foi nesse contexto, de negação da ciência e pandemia, que iniciamos um processo de aulas on-line na Universidade Federal do Pampa.

Como ministramos aulas na área das humanidades, temáticas atuais como o negacionismo, obscurantismo, apego a crenças religiosas e políticas, foram comuns em todas as aulas. Acadêmicos sempre traziam exemplos de diálogos com seus vizinhos e familiares que eram vítimas dessas crenças que circulavam na internet por meio de vídeos e textos. Durante as aulas surgiam muitas dúvidas e discussões sobre a forma como poderíamos abordar e levar pessoas com baixa escolaridade a refletirem melhor sobre o que liam e recebiam em seus celulares. Isso nos levou a pensar em uma proposta de produção de textos e vídeos reflexivos que pudessem contribuir com o processo de formação de uma consciência crítica para além do espaço universitário, frente à proliferação das falsas notícias pela internet. 
Apresentaremos a seguir o relato da experiência, iniciando com uma fundamentação teórica que nos ajudou a pensar e estruturar o projeto Educação popular nas redes. Em um primeiro momento, apresentaremos uma reflexão teórica em torno da função social do conhecimento e a concepção de educação popular em Freire (1994); em um segundo momento, relataremos mais especificamente a experiência em si.

\section{A Universidade e a função social do conhecimento}

A universidade promove uma série de exigências que, muitas vezes, levam o docente a se afastar da própria realidade. Em pesquisa realizada no doutorado, Guindani (2011) entrevistou docentes da pós-graduação (mestrado e doutorado) que revelaram ter se afastado de suas atividades de militância social em função das exigências do meio acadêmico. Os professores entrevistados na referida pesquisa são teólogos, muitos deles vinculados a movimentos e pastorais sociais, e relataram que sempre escreveram artigos e textos para jornais de bairro e para comunidades religiosas com o objetivo de contribuir com reflexões voltadas a questões sociais a partir do diálogo entre conceitos teóricos do campo teológico e a realidade das pessoas. Os professores entrevistados revelaram que, ao atuarem como docentes no mestrado, precisaram atender a inúmeras demandas de produção científica para um amplo leque de revistas, porém defrontaram-se com a necessidade de priorizar os periódicos com boa avaliação no Qualis $^{11}$, a fim de não prejudicar seus Programas de Pós-graduação. A pesquisa apontou que, na visão dos entrevistados, o que acaba prevalecendo é o "produtivismo acadêmico", analisado por Sguissardi e Silva Júnior (2009) como uma ideologia produzida pela própria burocracia da Capes e do $\mathrm{CNPq}$, que foi naturalizada e está sendo reproduzida em todos os espaços institucionais onde o professor pesquisador atua.

$\mathrm{Na}$ pesquisa, Guindani (2011) demonstrou que um professor entrevistado produziu mais de 150 textos em jornais e revistas, entre 2001 a 2010, o que revela uma inserção social do pesquisador que produzia para um público leigo com uma linguagem acessível. Porém, toda essa inserção social por meio da publicação em veículos de comunicação não possui o mesmo valor acadêmico para a Coordenação de Aperfeiçoamento de Pessoal de Nível Superior (Capes) ${ }^{12}$ que avalia a produção docente.

\footnotetext{
${ }^{11}$ O Qualis afere a qualidade dos artigos e de outros tipos de produção com base na análise dos veículos de divulgação e das produções contidas nas revistas. A classificação de periódicos é realizada pelas áreas de avaliação por meio de um processo periódico de avaliação, valendo-se dos indicativos da qualidade.

${ }^{12}$ A Coordenação de Aperfeiçoamento de Pessoal de Nível Superior - Capes é o órgão do Ministério da Educação responsável por avaliar os Programas de Pós-graduação do país. Um dos itens avaliados é a produção
} 
Para Kuenzer e Moraes (2005), a Capes instituiu, a partir de 1996, um modelo de avaliação centrado na produtividade. Tal modelo, segundo as autoras (2005, p. 1.347), gerou um "surto produtivista em que o que conta é publicar, não importa qual versão requentada de um produto, ou várias versões maquiadas de um produto novo". A quantidade na produção científica passa a instituir-se como uma meta, além do fato de que essa quantidade precisa ser direcionada para revistas com boa avaliação. Uma das consequências desses critérios de avaliação de produção científica é a redução de produção de textos para veículos de comunicação comunitários, como jornais de bairro ou de comunidades, associações, igrejas e movimentos sociais. O conhecimento científico acaba sendo socializado entre os cientistas e pesquisadores, mas deixa de contemplar as comunidades, deixa de atender às demandas mais diretas da sociedade. A função social do conhecimento passa a ser comprometida diante desse academicismo que pressiona pesquisadores a se direcionarem apenas a seus pares. A pesquisa de Guindani (2011) nos fez perceber que a circulação do conhecimento vai adquirindo, a partir dos critérios de avaliação da produção docente, um caráter endógeno, e perde um pouco seu papel de subsidiar lideranças populares e comunitárias. O conhecimento parece perder parte de sua função social mais direta. Enquanto docentes, somos muito mais incentivados, em função do currículo, a fazermos pesquisa e publicarmos resultados em revistas científicas do que a fazermos projetos de extensão e a contribuirmos de forma mais efetiva com as comunidades.

Por esse caminho, a realização de projetos mais acessíveis e participativos apresenta-se como alternativa de aproximação da universidade e comunidade. A realização de projetos com princípios de educação libertadora e popular, e que facilitam a maior participação e discussão dos problemas sociais urgentes, requer estratégias e espaços comunicacionais comuns. A discussão sobre a universidade, ou a produção de conhecimento crítico, fomenta a necessidade de pensar a aproximação da educação e da comunicação.

\section{A comunicação do conhecimento científico como educação popular}

Paulo Freire é considerado um dos primeiros teóricos da comunicação e de práticas comunicativas para a alfabetização popular. Portanto, quando se discute ou se pretende implementar a educação popular, é necessária a discussão da comunicação, seja tecnológica ou interpessoal. O educador enfatiza que "a educação é comunicação, é diálogo, na medida

científica dos professores que atuam nos Mestrados e Doutorados. Os critérios de avaliação podem ser conferidos no site (BRASIL, 2021). 
em que não é transferência de saber, mas um encontro de sujeitos interlocutores que buscam a significação dos significados" (FREIRE, 1975, p. 69). Desse modo, é importante que o educador, o pesquisador e os educandos interessados em promover a educação popular, também compreendam as lógicas comunicacionais de seu contexto e as utilizem de forma crítica e dialógica.

É por meio da comunicação que nos situamos no mundo, conhecemos, construímos e transformamos a realidade. Estar alheio ou não, compreender o funcionamento da comunicação, tecnológica ou não, é um problema quando se pretende tornar mais acessível os espaços e oportunidades de educação popular ou de crítica aos problemas sociais mais urgentes, ou seja, não se faz educação popular sem pensar, na mesma medida, em estratégias, em formas e canais de comunicação.

Iniciativas acadêmicas e populares, denominadas de Educomunicação, ou de comunicação para a educação, evidenciam que a produção do conhecimento prescinde de estratégias de comunicação para que não ocorra a simplificação ou a relativização da própria prática educacional: "como nossa educação nos ensinou a separar, compartimentar, isolar e não a unir os conhecimentos", é importante haver estratégias de comunicação que ampliem as possibilidades de crítica e de diálogo (MORIN, 2000). Assim, quando a intenção é a educação para a emancipação, os novos espaços de encontro e de comunicação se tornam estratégicos e indispensáveis. Em outras palavras, as tecnologias contemporâneas de comunicação, sobretudo as plataformas digitais e as redes sociais, dispõem de facilidades para a aproximação e o diálogo em tempos e espaços diferentes. O filósofo Pierre Lèvy (1998, p. 72) nos ajuda a entender que o tempo presente está cada vez mais regido pelas lógicas de comunicação capazes de aproximar, em um mesmo tempo e espaço, sujeitos antes dispersos:

trabalhar, viver, conversar fraternalmente com outros seres, cruzar um pouco por sua história, isso significa, entre outras coisas, construir uma bagagem de referências e associações comuns, uma rede hipertextual unificada, um contexto compartilhado, capaz de diminuir os riscos de incompreensão.

Portanto, a comunicação do conhecimento científico, numa perspectiva de educação popular, já é uma realidade tecnologicamente possível. Mesmo que nem todos estejam conectados ou possuam as tecnologias de forma gratuita, já se desenham possibilidades, tentativas e experimentos de produção do conhecimento de forma colaborativa, com grandes potenciais de educação popular, no sentido amplo e orgânico. Mesmo que o acesso tecnológico não seja de qualidade, já é possível perceber o aumento da procura, bem como da 
participação popular através das tecnologias móveis e da participação em redes sociais com propósitos educativos ${ }^{13}$.

\section{O projeto Educação popular nas redes}

A equipe que idealizou esse projeto, Educação popular nas redes, é composta por professores(as) e acadêmicos(as) que tiveram e têm forte atuação em movimentos sociais e sindicais, assim como muitos teólogos entrevistados na pesquisa de Guindani (2011). É diante disso que pensamos ser de extrema relevância construir novas possibilidades para sairmos das quatro paredes da universidade e contribuirmos com a organização dos pobres na luta pela sua emancipação social e política. E para isso, pensamos em nos apoiar no conceito de educação popular.

Para Hurtado (1993), a definição da educação popular se concebe no compromisso de classe, na sua ligação orgânica com o movimento popular. Freire (1994) considera que a educação popular está ancorada numa produção cooperativa, na atividade sindical, na mobilização e na organização da comunidade, e isso se dá dentro de um processo gnosiológico, ou seja, a produção do conhecimento nessa perspectiva se dá em diálogo com a realidade, com os desafios sociais que batem à nossa porta. Muraro e Silva (2014) nos apontam que nessa perspectiva da educação popular, construiremos uma educação democrática voltada para a conscientização das pessoas no sentido de lhes dar condições para reagir à massificação e ao assistencialismo, resistir à alienação, e ajudá-las a sair de sua condição de homem-coisa para homem-sujeito.

Marx (1984, p. 108) também nos ajuda nesse sentido ao abordar o conceito de práxis, ou seja, segundo ele "é na práxis que o homem tem de comprovar a verdade, isto é, a realidade, e o poder, o caráter terreno, do seu pensamento". Marx também faz uma crítica aos filósofos quando afirma que eles "têm apenas interpretado o mundo de maneiras diferentes", porém, segundo ele, “a questão é transformá-lo" (p. 111). Essa realidade é bastante perceptível no mundo acadêmico da pesquisa quando refletimos sobre muitas questões, fazemos entrevistas, analisamos indicadores e depois publicamos essas análises em revistas científicas e paramos nessa fase. Pensamos que precisamos dar um segundo passo na produção de um conhecimento em diálogo com a realidade das pessoas.

\footnotetext{
${ }^{13}$ De acordo com o Comitê gestor da internet, $82 \%$ dos jovens matriculados no ensino médio acompanharam as aulas através do smartphone. (PAINEL TIC-COVID-19, 2021).
} 
O nosso vínculo aos movimentos sociais é anterior à nossa entrada na universidade como docentes e acadêmicos(as), e nos levou a sempre nos inquietarmos com certa endogenia que sentíamos na dinâmica da vida acadêmica. Mesmo estando em constante diálogo com acadêmicos(as) provindos das mais diversas realidades culturais e sociais, mesmo atuando nas escolas, sentimos que precisamos, enquanto universidade, atuarmos de maneira mais efetiva no processo de transformação da realidade.

O contexto da pandemia, a partir do ano de 2020, nos obrigou a reduzir nossa atividade dentro de quatro paredes, porém com uma janela aberta ao mundo, que é a internet. Deparamo-nos assim, com a possibilidade de dialogarmos com a comunidade por meio da produção de material audiovisual e textos reflexivos que conseguissem socializar o conhecimento científico por meio de uma linguagem acessível às pessoas fora do ambiente acadêmico.

Inicialmente identificamos um foco, que seria o combate à proliferação de falsas notícias pela internet, bem como às crenças alimentadas em visões distorcidas de conceitos como vacinas, comunismo, direita, esquerda. Partindo desse foco, abrimos um canal no YouTube e uma página no Facebook e Instagram. Na apresentação do canal, explicitamos que o objetivo do espaço seria contribuir com o autoconhecimento e a transformação da sociedade a partir dos conhecimentos provindos do campo científico. O nome do canal do YouTube é "Ciêncialiberta", o qual foi inspirado no que o sociólogo Émile Durkheim afirma no seu livro Educação Moral:

De maneira geral, podemos dizer que compreendemos tanto melhor as coisas quanto mais simples elas são [...]. As coisas complexas, ao contrário, por serem complexas, só podem ser representadas de forma difícil e confusa. Disso resulta essa tendência a negar sua realidade... (DURKHEIM, 2008, p. 245).

Por isso Durkheim (2008, p. 252) defende que "é preciso dar à criança o sentimento da complexidade real das coisas". Para ele, é necessário haver "toda uma educação intelectual [...] e é para essa educação que pode contribuir o ensino elementar das ciências". Numa época em que presenciamos líderes políticos e comunicadores menosprezando a ciência, consideramos importante demonstrar que ela tem o papel de nos libertar das amarras do senso comum e das crenças limitantes. Defendemos a ideia de que o conhecimento científico contribui para a emancipação do indivíduo e da sociedade. Como já dito anteriormente, no Brasil vivenciamos um momento em que conhecimentos da área das ciências humanas são desprezados ou estereotipados como comunistas ou esquerdistas. Nessa esteira, foram 
proliferando muitas ideias que levaram algumas pessoas a aderirem a pensamentos simplistas e crenças alienantes, bem como a votarem em políticos que defendem ideias ultrapassadas e inapropriadas para a sociedade do século 21. Defendemos que, principalmente, as ciências humanas precisam ser valorizadas na construção de uma sociedade pensante e crítica, fundamentada em princípios humanos e civilizatórios, e não em crenças que reduzem realidades extremamente complexas a crenças simplistas e totalmente equivocadas. Fundamentados nessa reflexão, entendemos ser fundamental defendermos a ideia de que a ciência deve contribuir na libertação das crenças alienantes e limitantes, por isso então o nome do canal: "Ciêncialiberta".

O projeto foi então desenvolvido por meio da produção de textos para Facebook, vídeos e lives para Youtube. Apresentaremos abaixo, em um quadro, as temáticas de alguns vídeos, lives e textos produzidos com alguns comentários dos internautas.

Quadro 1 - Vídeos publicados no canal do YouTube

\begin{tabular}{|c|c|c|}
\hline $\begin{array}{c}\text { Título } \\
\text { Data de publicação } \\
\text { Visualizações* }\end{array}$ & Descrição do conteúdo & Comentários sobre o vídeo \\
\hline $\begin{array}{l}\text { A ciência te liberta - } \\
\text { apresentação do canal } \\
\text { 12/01/2021 } \\
323 \text { visualizações }\end{array}$ & $\begin{array}{l}\text { Objetivo: apresentar o perfil dos } \\
\text { conteúdos que serão veiculados } \\
\text { nos vídeos. } \\
\text { Conceitos e temas abordados: } \\
\text { crenças limitantes; valorização do } \\
\text { conhecimento científico; função } \\
\text { social do conhecimento. }\end{array}$ & $\begin{array}{l}\text { “Que bom! Precisamos que assuntos } \\
\text { relevantes à humanidade sejam } \\
\text { retratados e tratados com esse } \\
\text { caráter idôneo.” } \\
\text { "Professor, que bacana sua } \\
\text { iniciativa. Vou divulgar por aqui." }\end{array}$ \\
\hline $\begin{array}{l}\text { A discussão política } \\
07 / 03 / 2021 \\
219 \text { visualizações }\end{array}$ & $\begin{array}{l}\text { Objetivo: apresentar uma reflexão } \\
\text { sobre a importância da discussão } \\
\text { política com base em fatos e não } \\
\text { em opiniões. } \\
\text { Conceitos e temas abordados: } \\
\text { política; racionalidade; senso } \\
\text { comum. }\end{array}$ & $\begin{array}{l}\text { "Essas reflexões trazem a } \\
\text { importância de combatermos as } \\
\text { simplificações do pensamento, os } \\
\text { "achismos" e a reprodução de } \\
\text { sensacionalismos midiáticos." } \\
\text { "Que bom socializar o } \\
\text { conhecimento, a temperança, a }\end{array}$ \\
\hline
\end{tabular}




\begin{tabular}{|c|c|c|}
\hline & & $\begin{array}{l}\text { ética. Vemos que, métodos, formas } \\
\text { e conteúdos, devem ser observados } \\
\text { quando damos opiniões, e pior, } \\
\text { quando queremos ser formadores de } \\
\text { opinião. Grato professor." }\end{array}$ \\
\hline $\begin{array}{l}\text { Boi Bala Bíblia } \\
\text { 16/04/2021 } \\
126 \text { visualizações }\end{array}$ & $\begin{array}{l}\text { Objetivo: apresentar uma reflexão } \\
\text { em torno da relação entre o } \\
\text { fundamentalismo religioso e a } \\
\text { defesa de pautas conservadoras } \\
\text { no campo político e econômico. } \\
\text { Conceitos e temas abordados: o } \\
\text { sagrado e o profano; } \\
\text { fundamentalismo religioso e } \\
\text { político. }\end{array}$ & $\begin{array}{l}\text { "Muito bom professor! Me fez } \\
\text { refletir sobre qual valor nossa casa } \\
\text { 'precisa' ter além de nos abrigar." } \\
\text { "Esse trabalho de combate à } \\
\text { alienação política é muito } \\
\text { importante e necessário que se faça. } \\
\text { Explanações como essa do } \\
\text { professor Evandro, são muito } \\
\text { esclarecedoras, elucidativas e jogam } \\
\text { muita luz à obscuridade dos reais } \\
\text { objetivos e intenções da bancada } \\
\text { evangélica, e também de muitos } \\
\text { políticos corruptos que envolvem e } \\
\text { enganam os fiéis e alienados } \\
\text { políticos com discursos emanados } \\
\text { de contradições, e com a } \\
\text { exploração da cultural e tradicional } \\
\text { fé humana.” }\end{array}$ \\
\hline $\begin{array}{l}\text { Religião, ciência e } \\
\text { educação (Live) } \\
\text { 19/06/2021 } \\
30 \text { pessoas presentes } \\
\text { na live } \\
94 \text { visualizações }\end{array}$ & $\begin{array}{l}\text { Objetivo: promover um debate } \\
\text { em torno da necessidade de } \\
\text { abordarmos cientificamente a } \\
\text { religião dentro da escola, } \\
\text { buscando prevenir o surgimento } \\
\text { de crenças fundamentalistas entre } \\
\text { os adolescentes. } \\
\text { Conceitos e temas abordados: } \\
\text { ciências da religião; }\end{array}$ & $\begin{array}{l}\text { "Parabéns pela live. Assunto } \\
\text { importante para ser discutido com } \\
\text { professores de ensino religioso." } \\
\text { "O homem criou Deus para atender } \\
\text { às suas necessidades." } \\
\text { "Muito bom, parabéns pelo } \\
\text { belíssimo trabalho." }\end{array}$ \\
\hline
\end{tabular}




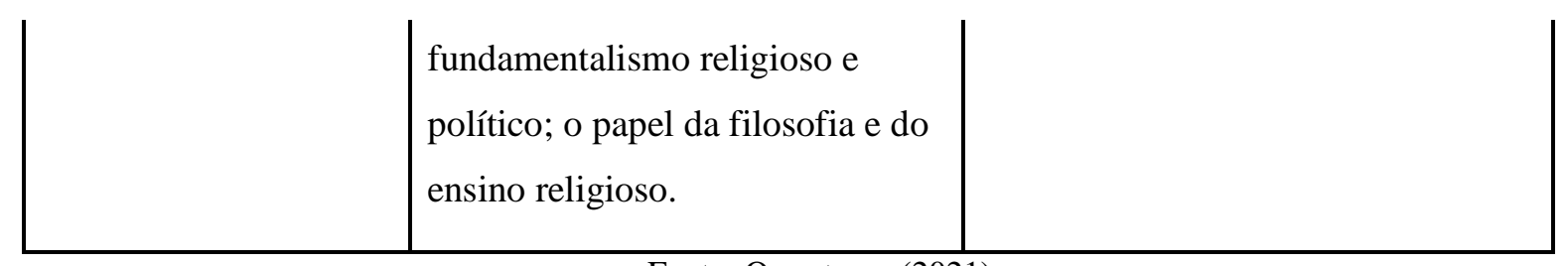

Fonte: Os autores (2021).

*O número de visualizações foi verificado no dia 21/6/2021.

Segue abaixo, no Quadro 2, alguns textos publicados no Facebook:

Quadro 2 - Textos publicados no Facebook

\begin{tabular}{|c|c|c|}
\hline $\begin{array}{c}\text { Título } \\
\text { Data de publicação }\end{array}$ & Descrição do conteúdo & Comentários \\
\hline $\begin{array}{l}\text { Religião e política } \\
01 / 04 / 2021\end{array}$ & $\begin{array}{l}\text { Objetivo: apresentar uma reflexão } \\
\text { sobre o fundamentalismo religioso } \\
\text { e político. } \\
\text { Conceitos e temas abordados: } \\
\text { fundamentalismo político; } \\
\text { fundamentalismo religioso. }\end{array}$ & $\begin{array}{l}\text { "Confesso que não entendo } \\
\text { muito sobre o conceito de } \\
\text { conservadorismo, religião e } \\
\text { essa pauta relacionada com a } \\
\text { família. Fico bem confuso } \\
\text { quando uma pessoa que se diz } \\
\text { pró-família, cristã } \\
\text { conservadora, mas já casou 3, } \\
4 \text { vezes, tem vários filhos com } \\
\text { diferentes mulheres. Isso é ser } \\
\text { conservador e pró-família? } \\
\text { Acho uma grande } \\
\text { contradição..." }\end{array}$ \\
\hline $\begin{array}{l}\text { "Uma reflexão para o } \\
\text { feriado" } \\
02 / 04 / 2021\end{array}$ & $\begin{array}{l}\text { Objetivo: apresentar uma reflexão } \\
\text { sobre a relação entre o } \\
\text { fundamentalismo bíblico e a } \\
\text { violência contra a comunidade } \\
\text { LGBTQI+. } \\
\text { Conceitos e temas abordados: } \\
\text { leitura literal dos textos bíblicos; } \\
\text { fundamentalismo religioso; ética e } \\
\text { violência contra o diferente. }\end{array}$ & $\begin{array}{l}\text { "Excelente! Gratidão por } \\
\text { compartilhar, professor. Algo } \\
\text { que me assusta é perceber a } \\
\text { falta de laicidade na } \\
\text { administração pública, no } \\
\text { macro e micro. Fico pensando } \\
\text { onde isso nos conduzirá..." }\end{array}$ \\
\hline
\end{tabular}




\begin{tabular}{|c|c|c|}
\hline $\begin{array}{l}\text { "A experiência do sentido } \\
\text { da vida e o respeito ao } \\
\text { diferente" } \\
04 / 04 / 2021\end{array}$ & $\begin{array}{l}\text { Objetivo: apresentar uma reflexão } \\
\text { sobre a relação entre a experiência } \\
\text { religiosa e o respeito ao outro. } \\
\text { Conceitos e temas abordados: } \\
\text { experiência religiosa; abertura ao } \\
\text { diferente. }\end{array}$ & $\begin{array}{l}\text { "Maravilha da vida abrir o } \\
\text { Facebook e ler um texto assim, } \\
\text { que impulsiona a uma reflexão } \\
\text { profunda e prazerosa, de } \\
\text { encontro à religiosidade que } \\
\text { pode estar presente em nossas } \\
\text { vivências cotidianas." } \\
\text { " Ora, se todos somos iguais, } \\
\text { mais coisas nos unem do que } \\
\text { nos dividem. Independente do } \\
\text { nosso posicionamento político, } \\
\text { religioso ou futebolístico, } \\
\text { temos algo em comum, somos } \\
\text { todos seres humanos." }\end{array}$ \\
\hline $\begin{array}{l}\text { "Somos seres cultivados } \\
\text { pelo outro" } \\
07 / 04 / 2021\end{array}$ & $\begin{array}{l}\text { Objetivo: apresentar uma reflexão } \\
\text { sobre o poder e o peso da cultura } \\
\text { sobre nossa forma de pensar e agir. } \\
\text { Conceitos e temas abordados: } \\
\text { cultura; moral coletivista. }\end{array}$ & $\begin{array}{l}\text { "Gratidão por seus textos, } \\
\text { professor, são sempre palavras } \\
\text { que nos trazem luz, clareando } \\
\text { possíveis obscuridades no } \\
\text { entendimento de nós mesmos." }\end{array}$ \\
\hline \begin{tabular}{llll} 
"O & \multicolumn{2}{r}{ assistencialismo } \\
cristão e & o & Estado \\
mínimo" & & \\
13/04/2021 & &
\end{tabular} & $\begin{array}{l}\text { Objetivo: apresentar uma reflexão } \\
\text { crítica sobre a relação entre a } \\
\text { prática do assistencialismo, o } \\
\text { conceito de caridade no } \\
\text { cristianismo e a legitimação da } \\
\text { lógica do Estado mínimo. } \\
\text { Conceitos e temas abordados: } \\
\text { assistencialismo cristão; Estado } \\
\text { mínimo; despolitização. }\end{array}$ & $\begin{array}{l}\text { "Concordo, professor, que } \\
\text { existe um desconhecimento, da } \\
\text { mídia e das pessoas, do que } \\
\text { são Políticas Públicas. Aqui } \\
\text { mesmo na nossa periferia de } \\
\text { São Borja tem pessoas vivendo } \\
\text { abaixo da linha da pobreza. É } \\
\text { assustador no Brasil, } \\
\text { alarmante, a falta de Política } \\
\text { Pública. Os jovens de } 15 \text { a } 29 \\
\text { anos são } 49,4 \text { milhões, sendo } \\
\text { que } 11 \text { milhões não estudam e } \\
\text { não trabalham." }\end{array}$ \\
\hline
\end{tabular}




\begin{tabular}{|c|c|c|}
\hline $\begin{array}{l}\text { "Ando devagar porque já } \\
\text { tive pressa" } \\
22 / 04 / 2021\end{array}$ & $\begin{array}{l}\text { Objetivo: apresentar uma reflexão } \\
\text { filosófica e antropológica sobre a } \\
\text { música "Tocando em frente". } \\
\text { Conceitos e temas abordados: } \\
\text { experiência; abertura ao novo; } \\
\text { experiência religiosa por meio da } \\
\text { arte. }\end{array}$ & $\begin{array}{l}\text { "Andar devagar é viver } \\
\text { melhor, com atenção plena, } \\
\text { usufruindo o gosto que a vida } \\
\text { tem, sentindo o sol ou o frio, } \\
\text { absorvendo o que o nosso } \\
\text { arredor tem a nos dizer... bom } \\
\text { dia, professor! Uma linda } \\
\text { quinta-feira!!!" } \\
\text { "Eu preciso aprender a andar } \\
\text { devagar! Mas vamos seguindo } \\
\text { e contemplando o que o tempo } \\
\text { nos permite, ótimo dia, } \\
\text { professor." } \\
\text { "Ter agressividade para fazer o } \\
\text { bem é fantástico (cirurgião, } \\
\text { bombeiro, salva-vidas...). Ter } \\
\text { paciência para andar devagar } \\
\text { acompanhando uma criança } \\
\text { em sua aprendizagem, um } \\
\text { idoso em suas limitações, } \\
\text { também o é. Continue } \\
\text { retratando o amor pra nós, } \\
\text { professor. Abraços." }\end{array}$ \\
\hline
\end{tabular}

Fonte: Os autores (2021).

Inicialmente, salientamos que a produção dos vídeos e textos exige um tempo de preparação, estudo, organização de roteiros, gravação e edição. Além desse tempo de produção, há o tempo da interação, sendo que muitos comentários dos internautas exigem retorno, pois apresentam dúvidas e questionamentos. Em muitas respostas se fazem necessárias novas leituras, novas abordagens e indicações de bibliografia. É muito comum termos comentários reducionistas, generalistas e até mesmo agressivos, o que exige maior cuidado na resposta, sempre com o objetivo de promover uma reflexão no internauta, o que se dá por meio de uma resposta compreensiva e não violenta. Em um dos comentários, por 
exemplo, um dos internautas afirmou que o texto era "esquerdista". Apenas esse comentário nos fez escrever muitas linhas explicando-lhe o conceito de esquerda e direita na política, o conceito de comunismo, socialismo, indicando-lhe bibliografias. Além disso, também tivemos o objetivo de manter o canal aberto com ele, valorizando o seu comentário e convidando-o a ler novos textos.

Essa metodologia de diálogo com os internautas, por meio das redes sociais, vem ao encontro do que Freire (1975, p. 69) considera importante para que a comunicação se torne educação, ou seja, que ela possa proporcionar o "encontro de sujeitos interlocutores que buscam a significação dos significados". Consideramos que todo esse trabalho - o qual muitas vezes toma nossos finais de semana, contribui para, conforme apontou Durkheim (2008), demonstrarmos a complexidade da realidade por meio da abordagem de conceitos na perspectiva científica. A produção de conteúdo em formato de vídeo e texto, direcionado à comunidade, contribui para o que Muraro e Silva (2014) apontaram sobre o papel da educação popular em promover uma educação democrática, voltada para a conscientização das pessoas, possibilitando condições para que reajam à massificação que muitas vezes se dá por meio da adesão acrítica a generalizações simplistas disseminadas na internet por meio de youtubers que não se fundamentam em pesquisas e conceitos teóricos na apresentação de seus vídeos.

Além de gravar vídeos e produzir textos para redes sociais, também realizamos lives com o objetivo de promover uma maior interação com o público de forma síncrona. A live intitulada "Religião, ciência e educação" teve o objetivo de contribuir no combate ao fundamentalismo religioso, oferecendo subsídios didáticos a professores de filosofia e ensino religioso. Outra live, que ainda será realizada, terá como título: "Família, escola e o fundamentalismo moral", que terá como público alvo alunos e familiares de ensino médio. O objetivo será esclarecer a diferença entre escola e família, ressaltando o papel da escola como disseminadora de conhecimento científico, o que pode conflitar com valores morais familiares. Um aspecto importante a ser destacado nessas duas lives é que elas tiveram, e terão, a participação de professores da educação básica. Esse também é um dos objetivos desse projeto: fomentar a parceria com a educação básica, pois assim podemos atingir um público mais amplo, que são as famílias dos alunos. Os textos do Facebook também estão servindo de subsídios didáticos para professores da educação básica, explicitado inclusive nos comentários das postagens. As lives ficam gravadas no canal e podem servir de subsídios a outros professores da educação básica. 


\section{Considerações finais}

Esse relato de experiência teve o objetivo de nos fazer refletir acerca da importância de, enquanto produtores do conhecimento, mantermos um canal sempre aberto de interlocução com a comunidade. Percebemos que a comunicação do conhecimento científico precisa cumprir uma função social, principalmente num momento em que o país está sendo assolado por comunicadores da desinformação.

Em períodos anteriores na história do Brasil, mais especificamente nas décadas de 1970 e 1980, tivemos a grande mídia hegemônica difundindo ideias distorcidas sobre conceitos no campo da política como "comunismo" e "socialismo". É possível perceber que os adultos de hoje (2000) absorveram essas visões distorcidas sobre política quando jovens e adolescentes, e hoje aderem com mais facilidade a ideias conservadoras proliferadas por governantes atuais. Além disso, reforçam e legitimam essas visões estereotipadas para seus filhos e netos nos espaços familiares. Atualmente podemos questionar o conceito de mídia hegemônica, mas não podemos negar que vivenciamos a presença de certa hegemonia do preconceito e superficialidade nas redes sociais. Jovens e adultos, portanto, recebem e compartilham mensagens legitimadoras de um processo simplificador da realidade.

Por isso, a criação de canais de comunicação que possam problematizar o senso comum dentro dos lares, dialogando com adultos e jovens, pode ser uma importante iniciativa promovida por profissionais do conhecimento dentro das universidades. Como bem ressaltou Lèvy (1998) e Morin (2000), podemos fazer uso de práticas educativas para além da formalidade da sala de aula com o objetivo de aproximar sujeitos que estavam dispersos. As redes sociais, ou mesmo a plataforma do YouTube, dialogam com sujeitos que podem estar longe da universidade, bem como distantes do pensamento científico, do diálogo problematizador da realidade.

O projeto Educação popular nas redes também pode ser uma experiência propulsora de reflexões que venham a contribuir no planejamento de políticas de extensão das instituições de ensino superior. Entendemos que cada área do conhecimento pode, por meio de uma política institucional, construir projetos de educação popular pelas redes sociais onde haja a construção de textos e vídeos com uma linguagem acessível à comunidade em geral. A construção e socialização do conhecimento não podem ficar restritas a veículos de comunicação acadêmicos, como revistas científicas. 


\section{Referências}

BRASIL. Ministério da Educação. Coordenação de Aperfeiçoamento de Pessoal de Nível Superior. Documento de Área. 2021. Disponível em: https://www.gov.br/capes/. Acesso em: 10 maio 2021.

DURKHEIM, E. A educação moral. Petrópolis: Vozes, 2008.

FREIRE, P. Pedagogia da esperança. Rio de Janeiro: Paz e Terra, 1994.

FREIRE, P. Comunicação ou extensão. Rio de Janeiro: Paz e Terra, 1975.

GUINDANI, E. O processo de produção do conhecimento nos PPGs de Teologia: da institucionalização à inserção no sistema Capes. 2011. Tese (Doutorado em Educação) Universidade Federal de Santa Catarina, Florianópolis, 2011. Disponível em:

https://repositorio.ufsc.br/xmlui/handle/123456789/95654. Acesso em: 10 maio 2021.

HURTADO, C. N. Educar para transformar, transformar para educar: comunicação e educação popular. Tradução de Romualdo Dias. Petrópolis, RJ: Vozes, 1993.

KUENZER, A.; MORAES, M. C. Temas e tramas na pós-graduação em Educação. Educação \& Sociedade, Campinas, v. 26, n. 93, p. 1.341-1.363, set./dez. 2005. Doi: 10.1590/S010173302005000400015. Disponível em: https://www.scielo.br/j/es/a/NCGYCZkVyFqBNwCTJnjWJ8x/?lang=pt. Acesso em: 15 ago. 2021.

LÈVY, P. A inteligência coletiva: por uma antropologia do ciberespaço. São Paulo: Loyola, 1998.

MARX, K.; ENGELS, F. A ideologia alemã. São Paulo: Moraes, 1984.

MORIN, E. Os sete saberes necessários à educação do futuro. 2 ed. São Paulo: Cortez; Brasília, DF: UNESCO, 2000.

MURARO, D. N.; SILVA, S. Conhecer para transformar: a epistemologia crítico-dialética de Paulo Freire. In: Reunião Anped Sul, 10., 2014. Disponível em:

http://xanpedsul.faed.udesc.br/arq_pdf/1196-0.pdf. Acesso em: 15 ago. 2021.

PAINEL TIC COVID-19. Pesquisa web sobre o uso da Internet no Brasil durante a pandemia do novo coronavírus: Painel TIC COVID-19 [livro eletrônico]. Núcleo de Informação e Coordenação do Ponto BR. São Paulo: Comitê Gestor da Internet no Brasil, 2021. Disponível em:

https://cgi.br/media/docs/publicacoes/2/20210426095323/painel_tic_covid19_livro_eletronico .pdf. Acesso em: 16 jun. 2021.

SGUISSARDI, V.; SILVA JÚNIOR, J. R. Trabalho intensificado nas federais: pósgraduação e produtivismo acadêmico. São Paulo: Xamã, 2009.

Submetido em 22 de junho de 2021. Aprovado em 30 de setembro de 2021. 